\title{
Analysis of cohort mortality from prostatic cancer in Spain, 1951-1983
}

\author{
AURELIO CAYUELA, ${ }^{1}$ JUAN R LACALLE, ${ }^{2}$ AND MIGUEL GILI ${ }^{2}$ \\ From ${ }^{1}$ the Department of Community Health, University of Alicante, and ${ }^{2}$ the Department of Social Medicine. \\ University of Seville, Spain.
}

ABSTRACT Prostatic cancer mortality rates in Spain were analysed for the period 1951-1983 by age groups. Five year interval age cohort trends were also studied.

A rising trend was seen over this period of time, although there has been some stabilisation during the recent past. Age cohort analysis shows a generation effect in those cohorts born before 1896, consistent with an increased exposure to environmental and/or occupational factors.

There is considerable international variation in the incidence of cancer of the prostate, the disease being very common in North America, particularly among blacks, and also in Scandinavia, and being rare in Japan and other oriental countries, with a 120-fold difference between the lowest and highest incidence rates. ${ }^{1}$

Analysis of mortality data reveal that the highest rates are reported from St Vincent and Grenadines, Martinique and Bermuda (countries where morbidity statistics are not available), followed by Sweden, Norway, Uruguay, Switzerland, Hungary, Belgium and some other European and Caribbean countries, while mortality rates reported from the USA and Canada are much lower. ${ }^{2}$

In Spain, prostatic cancer is the most common tumour of the male genitourinary system and the third most frequently occurring cancer among men, exceeded only by lung and stomach cancer. In addition to its obvious importance as a major source of morbidity and mortality, prostatic cancer is of epidemiological interest because of the many questions about its aetiology and because of the potential for identifying possible risk factors.

This paper presents the results of a study carried out in Spain on mortality trends from cancer of prostate over the period 1951-1983. Mortality is jointly influenced by age, secular trends (year of death) and birth cohort, and hence the analysis looks at mortality rates from these three points of view.

\section{Methods}

The main source of this study was the data on number of deaths attributed to prostatic cancer obtained from
Spain's National Institute for Statistics (INE) for the years 1951-1983 (6th and 7th Revision International Classification of Disease, code 177; 8th and 9th Revisions, code 185). ${ }^{3}$

Death rates per 100000 inhabitants were calculated using decennial census population figures. Intercensal populations were estimated by the linear interpolation method. Age standardised prostatic cancer mortality rates were calculated by the direct method, using the 1980 Spanish population as the standard population. The age specific prostatic cancer death rates for the 5 year age categories 55-59, 60-64, . ., 75-59 and $80+$ were calculated during the same time period.

Statistical tests were performed to determine whether time trends of prostatic cancer mortality were statistically significant. For the cohort analysis the age specific death rates were plotted against the year of birth. The age specific death rates were arranged in such a way that any line parallel to the $y$ axis joined the values for persons belonging to the same birth cohorts. ${ }^{4}$ The cohorts were designated by their central year of birth. The curves in the graph join persons dying at the same age, but belonging to different birth cohorts. In the period age contours, the death rates were plotted against the year of death.

\section{Results}

Mortality from prostatic cancer has had an average increase of 2\% per year from 1951 to 1983 in Spain. The total increase throughout the period has been $64 \%$, which is reflected in an increasing trend (fig 1) which is statistically significant (Pearson's correlation coefficient $=0.98, p<0.001$ ). The trend has shown two different phases: in the first phase, from 1951 to 1970 , 
250

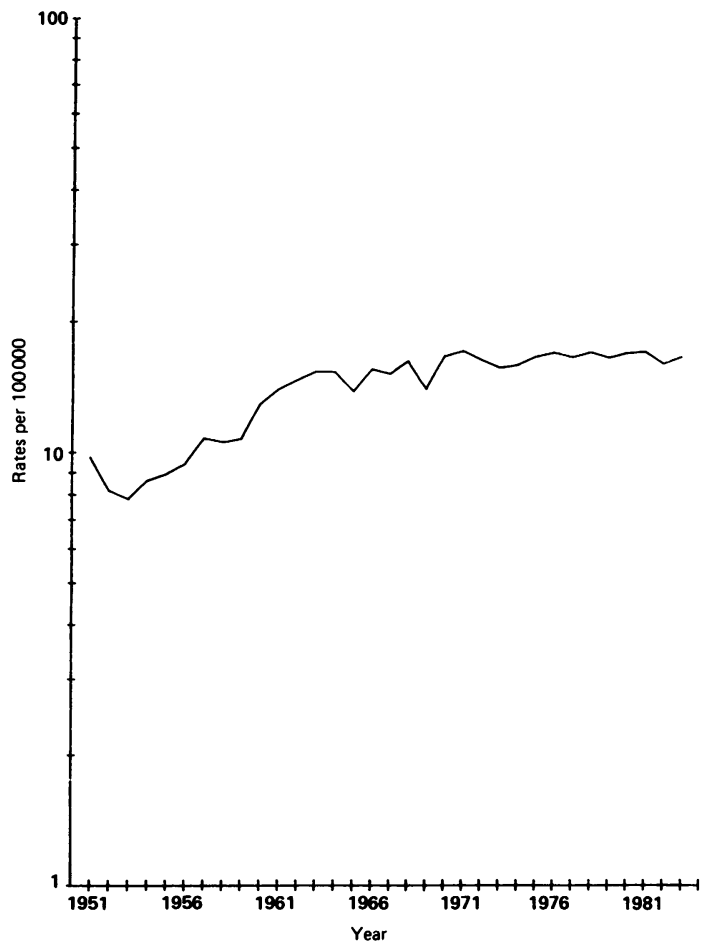

Fig 1 Age standardised prostatic cancer mortality rates, Spain, 1951-1983

the rates increased at $3.32 \%$ per year, while in the second phase, from 1971 to 1983 , the rates levelled off ( $0.07 \%$ per year).

Figure 2 shows the age specific death rates for prostatic cancer $v$ year of death, plotted semilogarithmically. Because few deaths took place among young people, analysis was restricted to mortality patterns after age 55 . No clearly rising trend is seen in the curves until the 60-64 year age group and above. A definite trend was not found in the 55-59 year age group.

The period age curves shown in fig 3 and the table have been reassembled with the abscissa indicating date of birth instead of date of death. In this arrangement, beginning with the birth year on the abscissa, each generation can be followed vertically upwards across the curves for succesive age groups. The data have again been plotted semilogarithmically. Here it becomes apparent that for successive birth year cohorts, up to 1891-1896, mortality rose steadily, but after 1896 it became stabilised.

Figure 4 (cross sectional mortality rates for prostatic cancer by 5 year age group) shows that prostatic cancer mortality rates increase linearly with age.

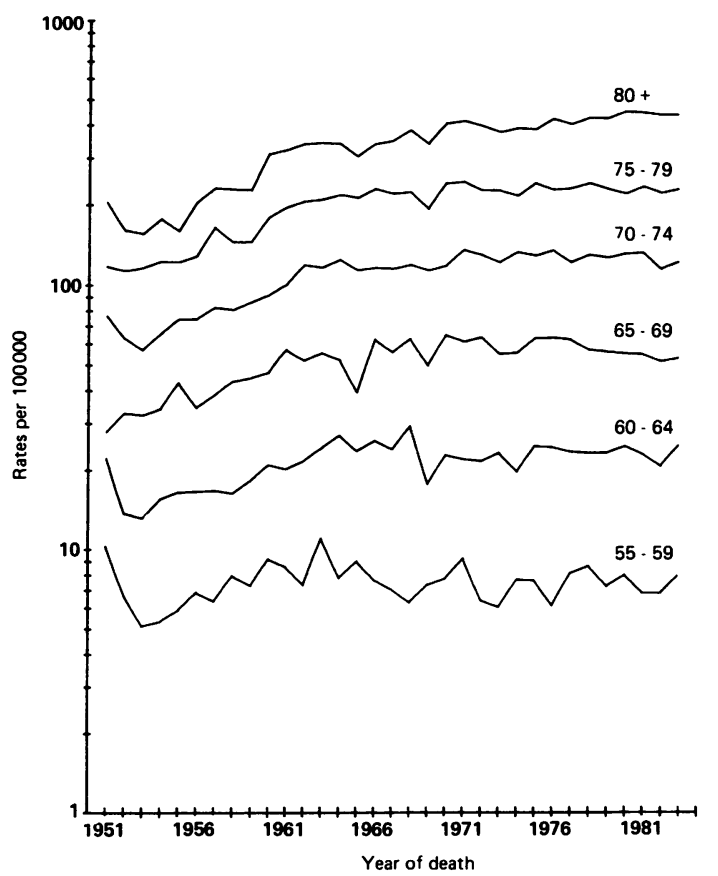

Fig 2 Age specific prostatic cancer rates $\mathbf{v}$ year of death, Spain, 1951-1983

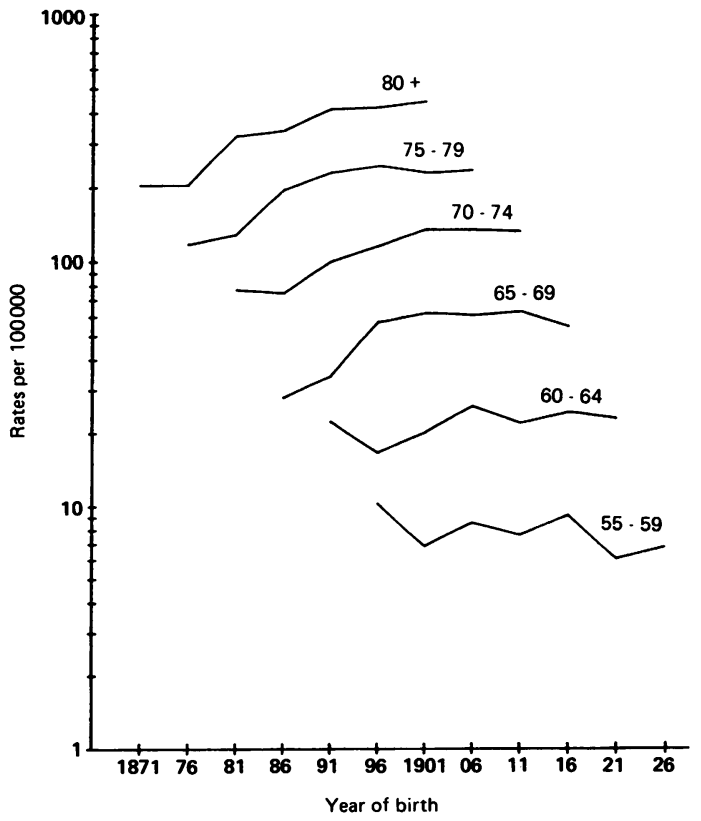

Fig 3 Age specific prostatic cancer rates $\mathrm{v}$ year of birth 
Table Age specific prostatic cancer mortality rates per 100000 , by year of birth

\begin{tabular}{llrllll}
\hline $\begin{array}{l}\text { Year of } \\
\text { Birth }\end{array}$ & $50-54$ & $55-59$ & $60-64$ & $65-69$ & $70-74$ & $75-79$ \\
\hline 1886 & - & - & - & 27.96 & 74.47 & 195.49 \\
1891 & - & - & 22.32 & 34.38 & $100 \cdot 18$ & 229.41 \\
1896 & - & 10.25 & 16.58 & 56.95 & $115 \cdot 88$ & 244.15 \\
1901 & 4.50 & 6.87 & 20.07 & 62.09 & 134.89 & $227 \cdot 16$ \\
1906 & 1.51 & 8.54 & 25.72 & 60.88 & 134.40 & 233.49 \\
1911 & 2.92 & 7.61 & 21.91 & 63.15 & 131.96 & - \\
1916 & 2.76 & 9.19 & 24.28 & 54.53 & - & - \\
1921 & 1.34 & 6.09 & 22.84 & - & - & - \\
\hline
\end{tabular}

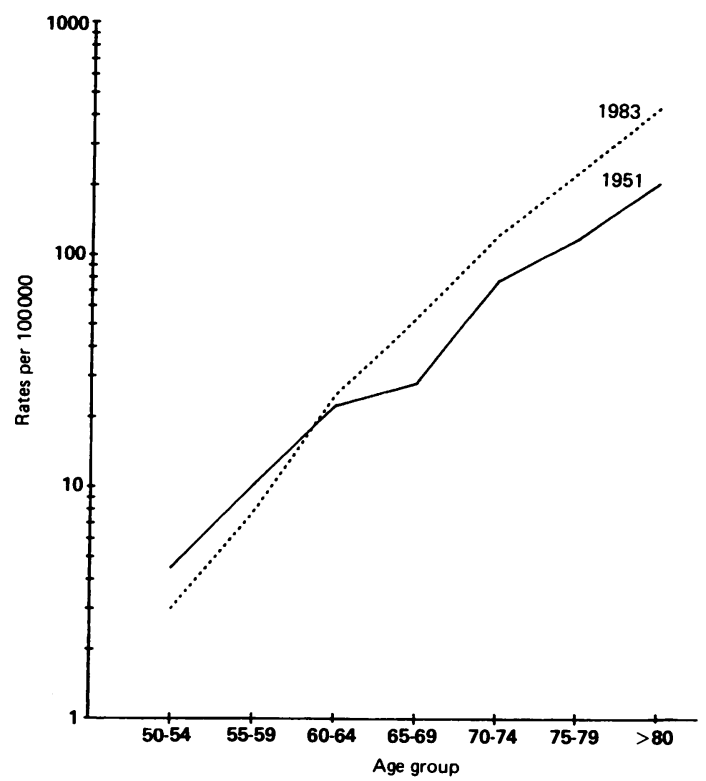

Fig 4 Cross sectional mortality rates for prostatic cancer, Spain, 1951 and 1983

\section{Discussion}

In this paper the magnitude of prostatic cancer in Spain has been evaluated only with regard to mortality, since no national reporting systems or periodic surveys defining the incidence and prevalence of cancer over the whole country are available. Therefore the possible changes in time trends, calculated on the basis of mortality, could be due to variations in lethality rather than due to variations in the levels of exposure of hypothetical risk factors. However, it seems likely that the lethality has not changed markedly over recent years in Spain.

Several factors may have affected the variations in mortality rates within the stated period, including demographic factors (growth and aging of the population), actual increase of risk or exposure factor, and the intersection of both these factors.

One might expect that the aging of the population results in a longer time of exposure to possible environmental risk factors, which would be shown in an increase in cancer rates, but this effect is removed by the use of adjusted rates.

Increase in mortality from prostatic cancer may also reflect changes in procedures for assigning cause of death on the death certificate, changes in rules for classifying the coding of cause of death on the death certificate, improvements in reporting the cause of death, or reductions in other causes of death. However, even when these factors are taken into account, the magnitude of the increase gives reason to believe that there has been an actual increase in prostatic cancer mortality in Spain.

The data from this study show an upward trend of prostatic cancer mortality in Spain, although this increase is due mainly to the increase in mortality after the age of 65. This pattern is similar to that seen in Chile, Czechoslovakia, Portugal and Sweden, where there has been an increase of about $2 \%$ per annum in age standardised mortality. ${ }^{2}$

Cancer of the prostate is a disease chiefly of old men. The incidence increases with age through the most advanced ages for which data are available. In Spain this pattern is clearly recognisable (fig 4). From our data we can interpret the age-time pattern of the death rates from prostate cancer as being due to a birth cohort phenomenon. We see that there is a regular increase in the rates with each successive birth cohort in each age group over 65 years. It implies that important determinants for the development of this disease occur early in the life of a cohort and that it is these early determinants that are changing with time. ${ }^{5}$ Generations born at the end of the 19th century showed a high risk of dying from prostate cancer and carried it throughout their lives; the condition waxed from one generation to the next, reached a peak, and then became stabilised in the subsequent generations.

Some authors have pointed out that spurious cohort effects can result from a sudden change in birth rate. ${ }^{6}$ This phenomenon could explain the cohort effect in our mortality data. However birth rates remained more or less stable throughout this century until the late 1970s, when they declined markedly. Birth rate changes can therefore be eliminated as a possible explanation for the observed cohort effect.

On the basis of these cohort analyses, we can conclude that mortality from prostate cancer has begun to stabilise, although period analysis still gives the impression of a continuing epidemic.

These temporal changes observed in prostatic cancer mortality in Spain, using cohort analysis, are not very different from those found in many other 
countries. Barrett ${ }^{7}$ analysed prostatic cancer mortality in England and Wales according to birth cohorts. Peak mortality rates occurred for a cohort of men born around 1886, suggesting that some factor or factors affected this group more than those born before or after this date. Ernster et $\mathrm{al}^{8}$ found that mortality rates for US non-whites were greatest for the cohort born between 1896 and 1900 . They suggest that the trend of rising mortality for non-whites will be reversed after the influence of this cohort on overall mortality is passed.

Despite the very high morbidity and mortality, however, little is known about the aetiology of this cancer and further studies are neccessary.

This study was supported in part by a grant from the Fondo de Investigaciones de la Seguridad Social (FISS).

Address for correspondence and reprints: Dr Aurelio Cayuela, Division de Medicina Preventiva, Departmento de Salud Comunitaria, Universidad de Alicante, San Vincente del Raspeig, Alicante, Spain.

\section{References}

${ }^{1}$ Waterhouse J, Muir C, Shanmugaratnam K, et al, eds. Cancer incidence in five continents, Vol IV. Lyon: International Agency for Research on Cancer scientific publication No. 42, 1982.

2 Zaridze DG, Boyle P, Smans M. International trends in prostate cancer. Int J Cancer 1984; 32: 223-30.

${ }^{3}$ Movimiento natural de la población (Defunciones según la causa de muerte). National Institute for Statistics (INE): Madrid, 1951-1979.

${ }^{4}$ Osmond C, Gardner MJ, Acheson ED, Adelstein AM. Trends in cancer mortality 1951-1980 (analyses by period of birth and death). Series DH1, No 11. London: Government Statistical Service, 1983: 71.

${ }^{5}$ MacMahon B, Pugh TF. Epidemiology-principles and methods. Boston: Little, Brown, 1970: 184-98.

${ }^{6}$ Clayton D. Models for temporal variation in cancer rates: age-period-cohort models. Stat Med 1987; 6: 469-81.

${ }^{7}$ Barrett JC. Cohort mortality and prostate cancer. J Biosoc Sci 1980; 12: 341-4.

${ }^{8}$ Ernster VL, Selvin S, Winkelstein W. Cohort mortality for prostate cancer among non-whites. Science 1978; 200: $1165-6$. 